\title{
Development of the hungarian version of the short dark triad questionnaire (SD3-HU): Psychometric properties and validity
}

\author{
Zsolt Péter Szabón ${ }^{1,2}$ (1) Andrea Czibor ${ }^{2} \cdot$ Judith Neve $^{1} \cdot$ Péter Restás $^{2} \cdot$ Márton Hadarics $^{3} \cdot$ Linda Szijjártó $^{1}$. \\ Evelin Simon ${ }^{3} \cdot$ Janka Laura Marót ${ }^{3} \cdot$ Ágota Kun $^{1} \cdot$ Tamás Bereczkei $^{2}$
}

Accepted: 1 November 2021

(C) The Author(s) 2021

\begin{abstract}
The present studies were aimed at developing the Hungarian version of the Short Dark Triad questionnaire (SD3-HU). The internal structure of the translated questionnaire was examined with confirmatory factor analysis and exploratory structural equation modeling. Then the construct and concurrent validity of the Hungarian version was tested. The obtained results were based on a total of seven independent samples $\left(N_{\text {TOTAL }}=2161\right)$. While the internal structure of the SD3-HU showed inconsistencies with that of the original SD3, it proved consistent with adaptations developed in other languages. The SD3HU showed adequate construct and concurrent validity. In line with the conceptual framework of, and previous empirical findings on the Dark Triad, each dark trait showed the expected associations with broad personality dimensions, sensation seeking, character strengths, work motivation, and counterproductive work behaviors. Furthermore, self-ratings on the SD3$\mathrm{HU}$ were consistent with peer ratings. In sum, the SD3-HU is a reliable and valid measure of the dark traits.
\end{abstract}

Keywords Dark triad $\cdot$ SD3 $\cdot$ Adaptation $\cdot$ Reliability $\cdot$ Validity

\section{Introduction}

Since the publication of the groundbreaking work of Paulhus and Williams (2002), the Dark Triad (DT) of personality has enjoyed continuous scientific attention and popularity. Paulhus and Williams (2002) defines the DT as a set of three overlapping yet distinct personality traits. The common features of the three dark traits include limited empathy, low agreeableness, exploitation of others, and limited honesty and humility (Paulhus \& Williams, 2002; Lee et al., 2013). At the same time, each dark trait is associated with distinctive features in terms of self-control, risk taking, temporal orientation, identity needs, aggression, and flexibility (Bereczkei, 2015, 2018; Jones \& Paulhus, 2010; Jonason et al., 2012). Machiavellianism is characterized by a pragmatic approach to life, low impulsivity, strategic long-term

\section{Zsolt Péter Szabó}

szabo.zsolt.peter@gtk.bme.hu

1 Budapest University of Technology and Economics, Magyar Tudósok körútja 2, Budapest 1111, Hungary

2 University of Pécs, Pécs, Hungary

3 Eötvös Loránd University, Budapest, Hungary planning and manipulative behavior focused on self-beneficial goals (Bereczkei, 2015, 2018; Paulhus \& Williams, 2002). It has been proposed that the core of Machiavellians' long-term strategies is behavioral flexibility (Bereczkei, 2015, 2018). Supporting this view, compared to individuals low on Machiavellianism (non-Machs), individuals high on Machiavellianism (high Machs) show high cognitive and neural skills in social activities such as reward-seeking, taskorientation, monitoring others, and inhibition of cooperative impulses. These social strategies allow them to flexible adapt to the changing environmental circumstances. Subclinical narcissism is often defined as uncooperative extraversion, which is associated with inflated self-esteem, a sense of entitlement, and aggressive responses to ego-threatening situations (Lee et al., 2013). Morf and Rhodewalt (2001) argue that individuals high on narcissism generally behave traitlike and lack behavioral flexibility. Subclinical psychopathy is characterized by low conscientiousness, antisocial, aggressive behavior, and impulsive risk taking (Lee et al., 2013). Bereczkei (2015) argues that psychopathy, compared to Machiavellianism, can be characterized by recklessness precisely because of a deficit in inhibiting aggressive impulses (see also Jones \& Paulhus, 2010). These distinctive features account for the general observation that the three 
dark traits are only moderately correlated (Jones \& Paulhus, 2014). It should be noted however that conceptual redundancy, especially the Machiavellianism-psychopathy redundancy, is discussed extensively in the literature (e.g., Muris et al., 2017; Vize et al., 2018a, 2018b) The main argument of the Machiavellianism-psychopathy redundancy hypothesis is that the overlap between Machiavellianism and psychopathy is so high that they cannot be considered distinct constructs, and Machiavellianism should be understood as secondary psychopathy (Muris et al., 2017; Vize et al., 2018a, 2018b).

The main difficulties that early studies of the DT faced were the uneconomically large size and questionable commensurability of the available self-report measures (Zhang et al., 2020). Moreover, many early studies focused on only one of the three dark traits (Jonason et al., 2012). These difficulties were addressed by Jones and Paulhus (2014), who developed the Short Dark Triad (SD3) questionnaire. The SD3 comprises 27 items, nine of which measures each dark trait. The authors' declared aim was to develop a short yet comprehensive measure in terms of the number of conceptual facets assessed. Each of the three trait measures covers four facets including reputation, cynicism, coalition building, planning (Machiavellianism), leadership, exhibitionism, grandiosity, entitlement (subclinical narcissism), antisocial behavior, erratic lifestyle, callous affect, and short-term manipulation (subclinical psychopathy). The SD3 provides an economical, comprehensive and valid measure of the dark traits (Jones \& Paulhus, 2014).

The conceptual framework of, and previous empirical findings on the DT suggest specific associations between the dark traits and broad personality dimensions. The HEXACO model defines personality by six dimensions: honesty-humility (sincere, fair, not greedy, modest), emotionality (fearful, anxious, dependent, sentimental), extraversion (positive social self-esteem, socially bold, enjoy social interaction, energetic), agreeableness (trust others, gentle, flexible, calm), conscientiousness (organized, diligent, thorough, prudent), and openness to experience (appreciate arts and natural wonders, curious, creative, unconventional) (Lee \& Ashton, 2004). All three dark traits are negatively associated with honesty-humility and agreeableness (Lee \& Ashton, 2014; Muris et al., 2017; Zhang et al., 2020). Subclinical narcissism is positively associated with extraversion (Zhang et al., 2020) and openness (Lee \& Ashton, 2005), while subclinical psychopathy is negatively associated with emotionality (Jonason \& Webster, 2010; Paulhus \& Williams, 2002) and conscientiousness (Paulhus \& Williams, 2002).

Previous studies have also explored the relationships between the DT and character strengths (Kaufman et al., 2019). Character strengths are trait-like cognitive, affective and behavioral features beneficial either to the self or to others. The VIA Classification of Strengths specifies 24 character strengths such as creativity, bravery, and leadership (Peterson \& Seligman, 2004). From a purely conceptual viewpoint, one could expect character strengths to be negatively related or unrelated to the dark traits, since those high on these traits are generally self-centered, manipulative and exploitative. However, Kaufman et al. (2019) point out that divergent patterns are also possible, that is, the DT may in some cases be associated with more prosocial, growth-oriented, and self-transcendent outcomes. The authors revealed that the SD3 composite measure (including subscores on all three dark traits) was positively associated with character strengths such as creativity, curiosity, judgment, bravery, leadership, and spirituality.

In addition to broad traits and character strengths, the dark traits are also positively associated with more specific dispositions such as risk taking and sensation seeking (Vize et al., 2018a, 2018b). The revised HEXACO Personality Inventory (HEXACO-PI-R) measuring broad trait dimensions, the International Personality Item Pool - Values in Action (IPIP-VIA) questionnaire assessing character strengths, and the 7-item Hungarian version of the Sensation Seeking Scale (SSS-7-HU) offer adequate measures for testing the construct validity of the SD3-HU.

The impact of the dark traits on workplace outcomes has been a particularly prolific area of research on the DT (O'Boyle et al., 2012). Individuals high in DT traits as compared to individuals low in these traits are less likely to engage in organizational citizenship behaviors (OCB) and more likely to show counterproductive work behaviors (CWB), while they are characterized by unethical behavioral tendencies in business, and corruption (see O'Boyle et al., 2012; Szabó et al., 2021). Measures of workplace variables, particularly including CWB, administered simultaneously with the SD3-HU provide adequate instruments to assess the concurrent validity of the SD3-HU.

Most previous empirical studies on the DT employed self-report measures of the dark traits, which were correlated with various attitudes, beliefs, dispositions and behaviors hypothetically associated with the DT. In addition to self-report measures, the inclusion of other-informant reports is strongly recommended for studies on DT (Muris et al., 2017). High positive correlations between matched self-ratings and peer ratings corroborate the validity of the tested measure. This is the case when, for example, individuals with high self-reported Machiavellianism are perceived as highly manipulative by their peers (Jones \& Paulhus, 2014). The inclusion of other informants in the adaptation of the SD3-HU provide further essential information on the validity of the measure.

The present studies were aimed at the adaptation and validation of the Hungarian version of the SD3. 


\section{Overview of the Present Studies}

The 27 items of the original SD3 were translated into Hungarian (for a detailed description of the procedure, see Study 1). In Study 1, the translated items were subjected to confirmatory factor analysis (CFA) and exploratory structural equation modeling (ESEM) in order to examine the psychometric properties of the SD3-HU. In Study 2, each of the three dark trait measures included in the SD3-HU was correlated with measures of broad personality dimensions, character strengths and sensation seeking in order to test the construct validity of the SD3-HU. In Study 3, each of the three dark trait measures was correlated with workplace variables (CWB, work motivation) in order to test the concurrent validity of the SD3-HU. In Study 4, the participants self-ratings on the SD3-HU were correlated with matched peer ratings given by their direct supervisors and peers on measures of relevant behaviors, attitudes, job performance, and traits. The specific hypotheses are presented under the respective studies.

\section{Study 1. Confirmatory Factor Analysis and Exploratory Structural Equation Modeling of the Hungarian Short Dark Triad Questionnaire (SD3-HU)}

Study 1 was aimed at examining the internal structure of the Hungarian translation of the SD3. A total of seven competing models tested with CFA and ESEM procedures were compared to establish which one would produce the best fit with the observed data, each model being based on the related literature (Jones \& Paulhus, 2014; Persson et al., 2017).

An ESEM procedure was employed because of the questionable effectiveness of CFA in internal structure assessment of personality measures similar to the SD3 (Marsh et al., 2014). Since the SD3 is a measure of three overlapping constructs, the three hypothetical factors were expected to show substantial cross-loadings. However, CFA models are based on clear-cut factor structures where items are only allowed to load on their main factors, while cross-loadings on the other factors are set to zero. Moreover, the goodnessof-fit of the models and the discriminant validity of the factors could also be undermined by these highly restrictive specifications (Marsh et al., 2014). In such cases, a viable alternative is offered by the ESEM method, which combines the benefits of exploratory and confirmatory factor analysis (Marsh et al., 2014). In previous studies of self-report measures similar to the SD3, employing an ESEM procedure generally improved model fit and deflated interfactor correlations, which in turn improved the discriminant validity of the factors, thus providing a more realistic representation of the data (Marsh et al., 2014). In line with this observation, the internal structure of the SD3-HU was examined with a combination of the more conventional CFA and the more effective ESEM, similarly to the methodology adopted by Zhang et al. (2020), who developed the Chinese version of the SD3. The ESEM models were expected to show the best fit with the observed data.

\section{Method}

\section{Participants and Procedure}

A total of 667 Hungarian full-time employees participated in the study, 663 of whom gave complete responses to the SD3. The sample included 449 women and 211 men, while 7 participants provided no data on gender. The participants' age varied between 20 and 67 years $(M=37.43, S D=11.41)$, not including the 242 missing responses. Four participants had many missing responses in the SD3 and were excluded from the analyses (remaining $N=663$ ). Sample size requirements for ESEM are hard to find, but our sample size met even the conservative recommendations for confirmatory factor analysis $(N=20$ times the number of variables, Mundfom et al., 2009).

Participation was voluntary, and no compensation were offered in return. The participants were recruited by snowball sampling conducted via social media and personal contacts. After giving informed consent, the participants completed the SD3 and provided basic demographic data. Finally, participants were thanked and debriefed. The research plan was approved by the research ethics review board of the university which the first author is affiliated with.

\section{Instruments}

\section{Dark Triad}

The three dark traits were measured with the Hungarian translation of the Short Dark Triad questionnaire (SD3; Jones \& Paulhus, 2014). ${ }^{1}$ The SD3 comprises 27 items, nine of which measures each dark trait including Machiavellianism, subclinical narcissism and subclinical psychopathy. The participants rated the extent to which each Likert item applied to them using a five-point scale ranging from Strongly disagree (1) to Strongly agree (5).

The adaptation procedure started with the translation of the original SD3 from English into Hungarian. Following the guidance provided by the authors of the original questionnaire and observing the relevant methodological

\footnotetext{
$\overline{{ }^{1} \text { For a copy }}$ of the Hungarian version, please contact the first author.
} 
protocol (Hambleton, 2001), two competent individuals prepared two independent Hungarian translations. The translators then compared their translations for inconsistencies, which they discussed until consensus on each concerned item was reached. This initial Hungarian version was backtranslated into English by a competent native Hungarian speaker, and the original and back-translated items were compared by a competent native English speaker. On the basis of the observed inconsistencies, the meaning of the concerned Hungarian items was optimally adjusted to that of the respective original English items. Importantly, two items included in the original SD3 were each replaced by an alternative item in the final Hungarian version, one item measuring Machiavellianism and one measuring psychopathy. Both alternative items were selected from the original item pool of the SD3 (see Jones \& Paulhus, 2014). Since the present studies were specifically aimed at testing the SD3 in a workplace context, the original item "I enjoy having sex with people I hardly know" were replaced with the item "I like to pick on losers", while the item "I like to use clever manipulations to get my way" were replaced with the item "Generally speaking, people won't work hard unless they have to", both of which alternatives are more pertinent to the given context. Further considerations also justified the use of alternative items. Namely, the thematization of sexuality raised the question of cultural appropriateness, while the Hungarian equivalent of manipulation is almost exclusively used with a negative connotation.

The SD3 was the only measure administered in Study 1, apart from the questions on basic demographic data (age, gender).

\section{Statistical Data Analysis}

The CFA of the SD3 was conducted in the R v. 4.0.2. software environment primarily using the lavaan package (Rosseel, 2012). Since no ESEM procedure is available in $\mathrm{R}$, the MPlus v. 8.0 latent variable modeling program was used for this purpose (Muthén and Muthén, 1998-2017).

The following seven competing models (five CFA and two ESEM models) were compared for their fit with the data obtained with the Hungarian SD3. (1) In Model A, the 27 items formed one single factor defining a general dark trait. (2) In Model B, the 27 items were divided into two factors, one comprising the items measuring Machiavellianism and psychopathy, the other including the items for narcissism. Interfactor correlation was allowed. (3) In Model C, the 27 items were divided into three factors including Machiavellianism, narcissism and psychopathy. Interfactor correlations were allowed. (4) Model D was a bifactor alternative for Model B, in which a general factor comprising all items was added to the two specific factors. (5) Model E was a bifactor alternative for Model $\mathrm{C}$, in which a general factor
Table 1 Fit Indices for Measurement and Structural Models (S1, $N=663$ )

\begin{tabular}{lllll}
\hline Model & $\square^{2}(d f)$ & CFI & RMSEA [90\% CI] & SRMR \\
\hline Model A & $1592.63(324)$ & .589 & $.077[.073, .081]$ & 0.091 \\
Model B & $1186.54(323)$ & 0.720 & $.064[.060, .068]$ & 0.078 \\
Model C & $1065.10(321)$ & 0.759 & $.059[.055, .063]$ & 0.072 \\
Model D & $761.23(296)$ & 0.849 & $.049[.045, .053]$ & 0.054 \\
Model E & $698.89(294)$ & 0.869 & $.046[.041, .050]$ & 0.051 \\
Model F & $869.53(273)$ & 0.928 & $.057[.053, .062]$ & 0.042 \\
Model G & $633.03(249)$ & 0.954 & $.048[.043, .053]$ & 0.034 \\
\hline
\end{tabular}

Notes. Model $\mathrm{A}=$ General Dark Trait (27 items, 1 factor); Model $\mathrm{B}=$ Dark Dyad (Mach + Psych $=1$ factor and Narc is a separate factor), interfactor correlation was allowed; Model $\mathrm{C}=$ Dark Triad (Mach, Psych, and Narc are separate factors), interfactor correlations were allowed; Model $\mathrm{D}=$ Model $\mathrm{B}+$ general factor; Model $\mathrm{E}=$ Model $\mathrm{C}+$ general factor; Model $\mathrm{F}=\mathrm{ESEM}, \mathrm{SD} 3$ items were entered as three separate factors with cross-loadings and interfactor correlations were allowed; Model $\mathrm{G}=$ Model $\mathrm{F}+$ general factor. $\square^{2}$ WLSMV chi square, $C F I=$ Comparative Fit Index, $R M S E A=$ Root Mean Square Error of Approximation, $S R M R=$ Standardized Root Mean Square Residual

comprising all items was added to the three specific factors. The two ESEM models were as follows. (6) In Model F, items for the three dark traits were entered as three separate factors with cross-loadings and interfactor correlations allowed. (7) Model G was a so-called B-ESEM model, an alternative for Model $\mathrm{F}$, in which a general factor comprising all items was added to the three specific factors with crossloadings allowed (see Jones \& Paulhus, 2014; Persson et al., 2017; Zhang et al., 2020).

Model fit assessment was based on the following five indices: (a) $\square^{2}$ (a non-significant value at $\mathrm{p}>.05$ indicating adequate model fit); (b) $\square^{2} / \mathrm{df}$ (indicating adequate fit below 5 and good fit below 2); (c) CFI (Comparative Fit Index; indicating adequate fit above .90 and good fit above .95); (d) RMSEA (Root Mean Square Error of Approximation; indicating adequate fit below .08 and good fit below .05); (e) SRMR (Standardized Root Mean Squared Residual; indicating adequate fit below .06) (Beauducel \& Wittmann, 2005; Heene et al., 2011). The parameter estimates were obtained with the robust WLSMV method (Weighted Least Square Estimator), which is best suited to the ordered categorical nature of Likert scales, since it does not assume multivariate normality (Beauducel \& Herzberg, 2006).

\section{Results and Discussion}

The fit indices obtained for the tested CFA and ESEM models are presented in Table 1.

In line with previous findings, Model $\mathrm{G}$ showed the best fit, which comprised the three specific dark traits and a 
Table 2 B-ESEM factor loadings for 27 items in Study 1

\begin{tabular}{|c|c|c|c|c|}
\hline Items & DT & F1(Mach) & F2(Narc) & F3(Psych) \\
\hline Mach1 & -.07 & .49 & -.08 & -.09 \\
\hline Mach2* & .24 & .41 & -.06 & .00 \\
\hline Mach3 & .53 & .37 & .11 & -.21 \\
\hline Mach4 & .41 & .33 & -.14 & -.39 \\
\hline Mach5 & .57 & .55 & .09 & .15 \\
\hline Mach6 & .60 & .47 & -.01 & .32 \\
\hline Mach7 & .14 & .55 & -.04 & .13 \\
\hline Mach8 & .45 & .39 & .01 & -.04 \\
\hline Mach9 & .14 & .50 & .18 & .19 \\
\hline Narc1 & .32 & .11 & .67 & .05 \\
\hline Narc2 & .15 & -.02 & .65 & -.01 \\
\hline Narc3 & 51 & -.03 & .42 & -.11 \\
\hline Narc4 & .53 & -.09 & .50 & -.03 \\
\hline Narc5 & .32 & .25 & .41 & -.04 \\
\hline Narc6 & .06 & -.05 & .37 & .06 \\
\hline Narc7 & .54 & -.17 & .34 & .01 \\
\hline Narc8 & .19 & -.07 & .51 & .04 \\
\hline Narc9 & .22 & .31 & .12 & .04 \\
\hline Psych1 & .62 & .08 & -.05 & .36 \\
\hline Psych2 & .12 & -.15 & .31 & .22 \\
\hline Psych3 & .66 & .12 & -.13 & .37 \\
\hline Psych4 & .59 & -.19 & .10 & .34 \\
\hline Psych5 & .46 & .22 & -.11 & .51 \\
\hline Psych6 & .58 & .25 & .02 & .45 \\
\hline Psych7 & .20 & -.08 & .13 & .16 \\
\hline Psych8* & .79 & -.31 & -.04 & .14 \\
\hline Psych9 & .76 & -.00 & .01 & .01 \\
\hline
\end{tabular}

Notes. Mach $=$ Machiavellianism, Narc $=$ Subclinical Narcissism, Psych $=$ Subclinical Psychopathy. The item order is following the original English version. Modified items are denoted with an asterisk: Mach2 (original: "I like to use clever manipulation to get my way", Hungarian: "Generally speaking, people won't work had unless they have to"), Psych8 (original: "I enjoy having sex with people I hardly know", Hungarian: "I like to pick on losers")

general dark trait with cross-loadings allowed. Factor loadings are presented in Table 2.

The obtained factor loadings showed that most items loaded on their respective specific factors above .30 , apart from one item for narcissism and four items for psychopathy. A total of 17 items loaded on the general dark factor. Of these items, 14 loaded on the general factor more strongly than on their respective specific factors. In sum, the obtained fit indices and factor loadings revealed that the internal structure of the SD3-HU generally met the theoretical expectations, that is, a measure of the three specific dark traits each was composed of a non-overlapping set of nine items, while the 27 items in combination provided a composite measure of a general dark trait. The three-factor B-ESEM model is acceptable with some caution. As Zhang and colleagues (Zhang et al., 2020) note, this model provides an ,informative and plausible representation of the data", while ,we remind the reader of interpreting the model fit with care" (p. 1164). The inter-factor correlations obtained for the B-ESEM model were consistent with those reported in the literature (see, e.g., Jones \& Paulhus, 2014; Persson et al., 2017): the coefficients obtained for Machiavellianism and narcissism, Machiavellianism and psychopathy, and psychopathy and narcissism were $r=.15, .38$ and .40 , respectively ( $p<.001$ in all three cases). The internal consistency indices obtained for the Machiavellianism, narcissism and psychopathy measures were also consistent with those reported in the literature (Cronbach's $\alpha=.76, .74$ and .74, respectively; see, e.g., Jones \& Paulhus, 2014).

\section{Study 2. Construct Validity of the SD3-HU}

Study 2 was tested the construct validity of the Hungarian SD3. Data obtained with the SD3-HU administered to three independent samples were correlated with data on broad personality dimensions (HEXACO-PI-R; Study2a), on character strengths (IPIP-VIA, Study 2b), and on sensation seeking (SSS7-HU; Study 2c). The DT are both theoretically and empirically related to broad personality dimensions, character strengths and sensation seeking. Narcissism was expected to be positively associated with extraversion, psychopathy was expected to be associated positively with emotional stability and negatively with conscientiousness, while all three dark traits were expected to be negatively associated with honesty-humility and agreeableness (Zhang et al., 2020). DT were generally expected to be negatively associated with most character strengths (Kaufman et al., 2019). Some expectations were considered: narcissism was expected to show positive associations with creativity (Martinsen et al., 2019) and leadership (Paunonen et al., 2006), while a positive relationship was also expected between psychopathy and bravery (Patton et al., 2018). Furthermore, several existing findings suggest a positive relationship between the DT and sensation seeking. Specifically, the DT show positive associations with impulsivity, risk taking, and low self-control (Jonason et al., 2012; Jones \& Paulhus, 2010), all of which are closely related to sensation seeking (Vize et al., 2018a, 2018b). Theoretically, Machiavellianism should be less correlated with these variables than psychopathy and narcissism (see for example Bereczkei, 2015 but cf. Vize et al., 2018a, 2018b).

\section{Study 2a. Associations between the Dark Traits and Broad Personality Dimensions}

\section{Method}

\section{Participants and Procedure}

A total of 506 participants (309 women and 197 men) completed the SD3-HU and the HEXACO-PI-R. The 
mean age of the sample was 37.18 years $(S D=11.34)$. One participant had missing responses in the SD3 and was excluded from the analyses (remaining $N=505$ ). This sample size met the recommendation for obtaining stable correlation coefficients (Schönbrodt \& Perugini, 2013), and also comparable to previous studies investigating the associations between the SD3 and HEXACO-PI-R (e.g., Dinić \& Wertag, 2018; Zhang et al., 2020). The participants were recruited by snowball sampling conducted via social media and personal contacts. They were presented with the SD3-HU, the HEXACO-PI-R, and some demographic questions, respectively. Finally, the participants were thanked and debriefed.

\section{Instruments}

\section{Dark Triad}

DT were measured with the SD3-HU developed in Study 1.

\section{Global Personality Dimensions}

The 100-item Revised HEXACO Personality Inventory (HEXACO-PI-R; Lee \& Ashton, 2004) was used to assess the following six global personality dimensions: HonestyHumility (e.g., I would never accept a bribe, even if it were large), Emotionality (e.g., I sometimes can't help worrying about little things), Extraversion (e.g., In social situations, I'm usually the one who makes the first move), Agreeableness (e.g., I am usually quite flexible in my opinions when people disagree with me), Conscientiousness (e.g., I plan ahead and organize things, to avoid scrambling at the last minute), and Openness to experience (e.g., I enjoy looking at maps of different places). The participants rated the extent to which each Likert item applied to them using a five-point scale ranging from Strongly disagree (1) to Strongly agree (5). Each of the six personality dimensions was measured with 16 items. All trait measures showed adequate internal consistency (Cronbach's $\alpha$ s ranged from .78 to .84$)$.

\section{Results and Discussion}

The correlations between the HEXACO trait measures and the DT are presented in Table 3.

The obtained results are comparable with those reported by Zhang et al. (2020), who also used the HEXACO-PI-R to test the construct validity of the Chinese SD3 (SD3-C). Their results are consistent with those obtained in Study 2a: all three dark traits showed significant negative correlations
Table 3 Associations Between Dark Personality Traits and All Study Variables (S2a, S2b, S2c)

Study $2 \mathrm{a}(N=505)$ : The associations between dark personality traits and HEXACO personality

\begin{tabular}{llll}
\hline & Mach & Narc & Psych \\
\hline EX & .03 & $.49^{* *}$ & -.06 \\
EM & -.02 & $-.26^{* *}$ & $-.21^{* *}$ \\
AG & $-.31^{* *}$ & $-.15^{* *}$ & $-.29 * *$ \\
CO & .01 & .03 & $-.33^{* *}$ \\
OP & .01 & $.18^{* *}$ & -.08 \\
HH & $-.42^{* *}$ & $-.48^{* *}$ & $-.52^{* *}$ \\
$\alpha$ & 0.79 & 0.74 & 0.76
\end{tabular}

Study $2 \mathrm{~b}(N=278)$ : The associations between dark personality traits and character strengths

\begin{tabular}{|c|c|c|c|}
\hline & Mach & Narc & Psych \\
\hline Beauty & -.04 & .06 & .10 \\
\hline Love & -.09 & $.16^{* *}$ & $-.19 * *$ \\
\hline Teamwork & $-.15^{*}$ & .06 & $-.19 * *$ \\
\hline Curiosity & -.02 & $.20 * *$ & -.02 \\
\hline Fairness & -.11 & -.09 & $-.19 * *$ \\
\hline Forgiveness & $-.20 * *$ & -.06 & $-.31 * *$ \\
\hline Gratitude & -.09 & -.01 & $-.29 * *$ \\
\hline Hope & .01 & $.18^{* *}$ & .06 \\
\hline Humor & .10 & $.26^{* *}$ & .02 \\
\hline Persistence & .10 & .12 & $-.15^{*}$ \\
\hline Honesty & -.01 & .05 & $-.24 * *$ \\
\hline Open-mindedness & .01 & .10 & $-.19 * *$ \\
\hline Kindness & $-.13 *$ & .03 & $-.32 * *$ \\
\hline Leadership & -.09 & $.16^{* *}$ & $-.14 *$ \\
\hline Love of learning & -.07 & .06 & $-.17 * *$ \\
\hline Modesty & -.00 & $-.26 * *$ & $-.16^{* *}$ \\
\hline Creativity & .08 & $.23 * *$ & .00 \\
\hline Perspective & .06 & $.21 * *$ & -.08 \\
\hline Prudence & -.03 & $-.21 * *$ & $-.34 * *$ \\
\hline Self-regulation & -.10 & -.02 & $-.23 * *$ \\
\hline Social Intelligence & -.11 & $.26 * *$ & $-.12 *$ \\
\hline Spirituality & $-.20 * *$ & $.16^{* *}$ & -.07 \\
\hline Bravery & -.03 & $.22 * *$ & $.20 * *$ \\
\hline Zest & -.11 & $.30 * *$ & .07 \\
\hline$\alpha$ & 0.68 & 0.67 & 0.66 \\
\hline
\end{tabular}

Study $2 \mathrm{c}(N=256)$ : The associations between dark personality traits and sensation seeking

\begin{tabular}{llll} 
& Mach & Narc & Psych \\
SSS7 & $.15^{*}$ & $.34^{* *}$ & $.38^{* *}$ \\
$\alpha$ & 0.79 & 0.70 & 0.74 \\
\hline
\end{tabular}

Notes. Mach $=$ Machiavellianism, Narc $=$ Subclinical Narcissism, Psych $=$ Subclinical Psychopathy, EX = Extraversion, EM=Emotionality, $\mathrm{AG}=$ Agreeableness, $\mathrm{CO}=$ Conscientiousness, $\mathrm{OP}=$ Openness, $\mathrm{HH}=$ Honesty-Humility, SSS7 $=$ Sensation seeking

$* p<.05, * * p<.01$ 
with honesty-humility and agreeableness, while narcissism was positively related to extraversion, and psychopathy was negatively related to conscientiousness.

\section{Study $\mathbf{2 b}$. Associations between the Dark Traits and Character Strengths}

\section{Method}

\section{Participants and Procedure}

A total of 279 full-time employees (115 men and 163 women, one participant did not answer this question) participated in the study, of whom 266 were aged under 25 years, and 13 were aged 26 to 35 years. Of all participants, 97 had been employed for less than a year, 124 for one to five years, and three participants for more than five years. The overwhelming majority (98.2\%) fulfilled a non-managerial position. We dropped one participant who did not complete the IPIP-VIA from the analyses. The resulting sample size was 278This sample size met the recommendation for obtaining stable correlation coefficients (Schönbrodt \& Perugini, 2013).

Data were collected as part of a larger research project. Only the measures relevant to the present study are detailed below. The participants were presented with the SD3-HU, the IPIP-VIA questionnaire assessing character strengths (along with other self-report measures), and some demographic questions, respectively.

\section{Instruments}

\section{Dark Triad}

DT were measured with the SD3-HU developed in Study 1.

\section{Character Strengths}

Character strengths were assessed with a short form of the International Personality Item Pool - Values in Action (IPIPVIA) questionnaire (Goldberg et al., 2006). The self-report questionnaire measures the same character strengths as those assessed by the Values in Action Inventory Strength (Peterson \& Seligman, 2004). Each character strength was measured with four items selected by one of the authors of the present paper, who translated the IPIP-VIA into Hungarian. The items were selected so as to cover as many conceptual facets of each character strength as possible. The participants rated the extent to which each Likert item applied to them using a five-point scale ranging from Very much unlike me (1) to Very much like me (5).

\section{Results and Discussion}

Table 3 presents the correlations between the assessed character strengths and the three DT measures.

The results revealed no positive relationship between Machiavellianism and any of the character strengths. Machiavellianism was negatively associated with teamwork, forgiveness, kindness, and spirituality. Psychopathy was positively associated with bravery only, while it was negatively associated with love, teamwork, fairness, forgiveness, gratitude, perseverance, honesty, curiosity, kindness, leadership, love of learning, humility, prudence, selfregulation, and social intelligence. Among the three dark traits, narcissism showed the largest number of significant positive correlations with character strengths including love, curiosity, hope, humor, leadership, creativity, perspective, social intelligence, spirituality, bravery, and zest. At the same time, narcissism was negatively related to humility and prudence.

The obtained findings are in line with those reported in the literature. Several recent studies pointed out marked differences between the dark triad traits. Studies on the positive aspects of the dark triad traits contrasted narcissism with the other two traits (e.g., Papageorgiou et al., 2019). Some authors go as far as questioning the adequacy of operationalizing narcissism as a dark trait, due to its many positive features (e.g., mental toughness, resilience; Papageorgiou et al., 2019). Papageorgiou et al. (2019) even suggested "that the inclusion of narcissism in the malevolent side of human personality may need to be reconsidered" (p. 1251). The obtained positive associations between narcissism and character strengths such as leadership, creativity, and curiosity are consistent with previous findings reported in the literature (e.g., Paunonen et al., 2006; Martinsen et al., 2019). Nor is it surprising that psychopathy was positively associated with bravery, given that one definitive feature of psychopathy is recklessness, besides disinhibition and meanness, as defined by the triarchic model of psychopathy. Certain features of psychopathy such as a lack of fear, recklessness and risk taking may under certain conditions result in behaviors adequately described as bravery or even heroism (Patton et al., 2018). In sum, the observed associations between the dark trait measures of the SD3-HU and character strengths are consistent with the relevant findings reported in the literature, which confirms the construct validity of the SD3-HU. 


\section{Study 2c. Associations between the Dark Traits and Sensation Seeking}

\section{Method}

\section{Participants and Procedure}

A total of 256 participants (148 women and 108 men) completed the SD3-HU and the SSS-7-HU questionnaires. This sample size met the recommendation for obtaining stable correlation coefficients (Schönbrodt \& Perugini, 2013). The mean age of the sample was 37.12 years $(S D=11.99)$. We did not exclude any participants. Data were collected as part of a larger research project, whose major findings were published previously (Szabó et al., 2018). As part of a larger test battery, the participants were presented with the SD3-HU and the SSS-7-HU, respectively. Finally, the participants were thanked and debriefed.

\section{Instruments}

\section{Dark Triad}

DT were measured with the SD3-HU developed in Study 1.

\section{Sensation Seeking}

Sensation seeking was measured with the SSS-7-HU (Andó et al., 2009), which is a 7-item short Hungarian version of the Sensation Seeking Scale V. Each item consists of a pair of statements (A and B), of which respondents select the one which better describes them. Each sensation-avoiding response alternative scores 0 point, while each sensationseeking alternative scores 1 point, thus the total scale score ranges from 0 to 7 points, higher scores indicating higher levels of sensation seeking.

\section{Results}

Table 3 presents the observed correlations between sensation seeking and the three DT measures.

The results revealed that sensation seeking had significant positive associations with all three dark traits. In order to test the simultaneous effects of the three dark traits on sensation seeking, regression analysis was conducted with sensation seeking entered as the dependent variable and the three dark traits entered as predictors. The overall regression model proved significant $(F(3,251)=18.06, p<.001$, adjusted $\left.R^{2}=0.18\right)$. Of the three predictors, two showed significant explanatory power including narcissism $(\beta=.21, S E=.21$, $p<.01)$ and psychopathy $(\beta=.30, S E=.22, p<.01)$, whereas Machiavellianism was not a significant predictor $(\beta=-.04$, $S E=.18, p=.50)$.

\section{Discussion}

The observed associations of the three trait measures of the SD3-HU with the broad personality dimensions, the character strengths, and sensation seeking are in line both with the theoretical conceptualization of the DT and with the related previous empirical findings, which confirms the construct validity of the SD3-HU. Study 3 was aimed at testing the concurrent validity of the SD3-HU in a workplace context.

\section{Study 3. Concurrent Validity of the SD3-HU: Associations of the Dark Traits with Work Motivation and Counterproductive Work Behaviors}

There is an ample and continuously increasing amount of literature on the workplace outcomes associated with the dark traits (O’Boyle et al., 2012; Szabó et al., 2021). Counterproductive work behaviors (CWB) are discretionary behaviors that violate organizational rules and cause harm to the organization as a whole or to individual coworkers. The available findings show that high-DT individuals are more likely to engage in CWBs, which equally holds true for all three dark traits (O’Boyle et al., 2012; Szabó et al., 2021). Less consistent findings have been reported on the associations between the DT and work motivation. Gagné et al. (2015) makes a distinction between six types of work motivation including amotivation, extrinsic regulation - social, extrinsic regulation - material, introjected regulation, identified regulation, and intrinsic motivation. Amotivation is defined as one's lack of motivation for one's work activity. Extrinsic motivation is defined as being instrumentally motivated for one's work activity. Extrinsic motivation has two subtypes including social extrinsic regulation and material extrinsic regulation. Social extrinsic regulation is defined as one's motivation for being accepted by, and/or avoiding negative social feedback from one's coworkers. Material extrinsic regulation is defined as one's motivation for gaining and/or keeping material benefits (e.g., salary, job). Intrinsic motivation is defined as being motivated for one's work activity by the rewarding features of the activity itself (e.g., the pleasure found in the activity). Introjected regulation is defined as one's motivation for meeting one's internalized standards (e.g., feeling proud of one's achievements, avoiding feelings of shame accompanying failures). Identified regulation is defined as being motivated by the personal values one associates with one's work activity (e.g., attributing personal significance to the activity). The six types of work motivation were measured with the Multidimensional 
Work Motivation Scale (MWMS) developed by Gagné et al. (2015). To the authors' knowledge, the present study is the first to examine the relationship between this work motivation model and the DT. Previous findings provide useful information about the probable associations between work motivation and DT. Specifically, all three dark traits were expected to be positively associated with material extrinsic regulation (Rosenthal \& Pittinsky, 2006; Górnik-Durose \& Pilch, 2016; Prusik \& Szulawski, 2019). Furthermore, Machiavellianism and psychopathy were expected to be positively associated with amotivation (Kessler et al., 2010), while narcissism was expected to be positively associated with social extrinsic regulation (i.e., with one's motivation for gaining positive social feedback; see Górnik-Durose \& Pilch, 2016; Prusik \& Szulawski, 2019) and with introjected and identified regulation (see, e.g., Prusik \& Szulawski, 2019, who found that narcissism positively correlated with goal internalization and internal self-concept).

In order to test the concurrent validity of the SD-3-HU, the three dark trait measures were correlated with the 10-item Counterproductive Work Behavior Checklist (CWB-C; Spector et al., 2010) and with the six types of work motivation assessed with the MWMS (Gagné et al., 2015), all of which were administered to each participant in one session.

\section{Method}

\section{Participants and Procedure}

A total of 370 full-time employees (92 men and 253 women) participated in Study 3, of whom 115 were aged 18 to 29 years, 50 were aged 30 to 39 years, 109 were aged 40 to 49 years, 59 were aged 50 to 59 years, and 12 were aged over 60 years. Of all participants, 254 fulfilled a non-managerial position at the time of data collection. The 91 participants fulfilling a managerial position included 27 lower-level managers, 48 middle-level managers and 16 upper-level managers. Of all participants, 125 had been employed by their current employers for more than 10 years, 67 for 5 to 10 years, 44 for 3 to 4 years, and 61 for 1 to 2 years. We dropped twenty-five participants who did not complete the measures from the analyses. The resulting sample size was 345 . The resulting sample size met the recommendation for obtaining stable correlation coefficients (Schönbrodt \& Perugini, 2013). The participants were presented with the SD3-HU, the CWB-C, the MWMS, and some demographic questions, respectively.

\section{Instruments}

\section{Dark Triad}

The dark traits were measured with the SD3-HU developed in Study 1.

\section{Counterproductive Work Behaviors}

CWB were assessed with the 10-item Counterproductive Work Behavior Checklist (CWB-C; Spector et al., 2010). Of the 10 items, five concerned CWB toward the organization (e.g., Came to work late without permission), while five items addressed CWB toward individuals at the workplace (e.g., Insulted or made fun of someone at work). The participants rated the frequency at which they had done each of the listed behaviors on their current job using a five-point scale ranging from Never (1) to Every day (5). Adopting the procedure employed by Spector et al. (2010), the mean score of the 10 items was used as an overall measure of counterproductive work behaviors. The overall measure showed adequate internal consistency (Cronbach's $\alpha=.76$ ).

\section{Work Motivation}

Work motivation was measured with the Multidimensional Work Motivation Scale (MWMS; Gagné et al., 2010). The participants rated each of the 19 Likert items on a sevenpoint scale ranging from Strongly disagree (1) to Strongly agree (7). The MWMS assesses six types of work motivation including amotivation (e.g., I don't know why I'm doing this job, it's pointless work; $\alpha=0.79)$, extrinsic regulation - social (e.g., To avoid being criticized by others; $\alpha=0.62$ ), extrinsic regulation - material (e.g., Because others will reward me financially only if I put enough effort in my job; $\alpha=0.59$ ), introjected regulation (e.g., Because it makes me feel proud of myself; $\alpha=$ ), identified regulation (e.g., Because putting efforts in this job has personal significance to $m e ; \alpha=0.77$ ), and intrinsic motivation (e.g., Because the work $I$ do is interesting; $\alpha=0.80$ ).

\section{Results and Discussion}

Table 4 presents the correlations of the three DT measures with CWB and with work motivation, along with the descriptive statistics and the Cronbach's $\alpha$ coefficients for the DT measures.

Machiavellianism had significant positive associations with the two types of extrinsic regulation and with amotivation, while it was negatively associated with intrinsic motivation. No significant correlation was found between narcissism and any of the assessed types of work motivation. Psychopathy was associated positively with amotivation and material extrinsic regulation and negatively with identified regulation and intrinsic motivation. All three dark traits were positively associated with counterproductive work behaviors.

In order to test the simultaneous effects of the three dark traits on work motivation and CWB, regression analyses were conducted with each type of work motivation and the 
Table 4 Associations Between Dark Personality Traits and All Study Variables $(\mathrm{S} 3, N=345)$

\begin{tabular}{llll}
\hline & Mach & Narc & Psych \\
\hline Intrinsic motivation & $-.15^{* *}$ & .02 & $-.24^{* *}$ \\
Amotivation & $.22^{* *}$ & -.02 & $.19^{* *}$ \\
Extrinsic Regulation Material & $.29^{* *}$ & .01 & $.16^{* *}$ \\
Extrinsic Regulation Social & $.28^{* *}$ & .01 & .05 \\
Identified regulation & -.07 & .01 & $-.18^{* *}$ \\
Introjected regulation & .03 & .04 & -.01 \\
CWB & $.23^{*}$ & $.13^{*}$ & $.45^{* *}$ \\
$\alpha$ & 0.71 & 0.76 & 0.76 \\
\hline
\end{tabular}

Notes. Mach $=$ Machiavellianism, Narc $=$ Subclinical Narcissism, Psych $=$ Subclinical Psychopathy, $\mathrm{CWB}=$ Counterproductive Work Behaviors. ${ }^{*} p<.05, * * p<.01$

CWB-C total score entered as the dependent variables and the three dark traits entered as predictors in each model. All overall regression models proved significant at $p<.01$, except the model for introjected regulation $(p=.63)$. Intrinsic motivation was significantly predicted (adjusted $\left.R^{2}=.08, F(3,340)=8.736\right)$ by narcissism $(\beta=.15$, $S E=.10, p=.009)$ and psychopathy $(\beta=-.29, S E=.12$, $p<.001)$. Amotivation was significantly predicted by all three dark traits (adjusted $R^{2}=.07, F(3,340)=8.353$ ) including Machiavellianism $(\beta=.16, S E=.12, p=.007)$, narcissism $(\beta=-.23, S E=.11, p=.038)$, and psychopathy $(\beta=.17, S E=.14, p=.009)$. Material extrinsic regulation was significantly predicted by Machiavellianism (adjusted $R^{2}=.09, F(3,340)=11.300, \beta=.28, S E=.12$, $p<.001)$. Social extrinsic regulation was also significantly predicted by Machiavellianism (adjusted $R^{2}=.09$, $F(3,340)=10.617, \beta=.32, S E=.12, p<.001)$. Identified regulation was significantly predicted (adjusted $R^{2}=.04$, $F(3,340)=5.231)$ by narcissism $(\beta=.12, S E=.10, p=.05)$ and psychopathy $(\beta=-.24, S E=.12, p<.001)$. CWB were significantly predicted by psychopathy (adjusted $R^{2}=.21$, $F(3,335)=30.110, \beta=.48, S E=.05, p<.01)$.

The obtained findings are in line with those reported in the literature (Kessler et al., 2010; Rosenthal \& Pittinsky, 2006; Górnik-Durose \& Pilch, 2016; Prusik \& Szulawski, 2019; Szabó et al., 2021). Specifically, Machiavellianism is associated with generally low work motivation and instrumental motivation. Psychopathy is also associated with low work motivation, particularly regarding intrinsic motivation, and with CWB. Narcissism is generally associated with higher levels of work motivation, as reflected in its negative relationship with amotivation and positive relationship with identified regulation and intrinsic motivation. In sum, the associations of the trait measures of the SD3-HU with work motivation and counterproductive work behaviors are consistent with relevant previous findings, which confirms the concurrent validity of the SD3-HU.

\section{Study 4. Peer Ratings}

Study 4 was aimed at corroborating the validity of the SD3-HU in a workplace context by means of peer ratings. The inclusion of other-informant reports is important for a number of reasons, including these: it can circumvent fake-good reporting biases, and also the problem of inaccurate self-assessments (Muris et al., 2017). Specifically regarding the SD3-HU, individual coworkers' self-ratings and peer ratings were expected to be highly similar on each dark trait measure. That is, participants with high self-reported Machiavellianism were expected to be perceived by their peers as cynical, manipulative strategists with excellent coalition building skills; those with high self-reported psychopathy were expected to be perceived as prone to antisocial behavior, callousness and an erratic lifestyle; and those with high self-reported narcissism were expected to be perceived as prone to grandiosity, exhibitionism and a sense of entitlement. The peer-rating-based validity of the SD3-HU was tested with two samples. Study 4 a was conducted with a heterogeneous convenience sample, while Study $4 \mathrm{~b}$ focused on a homogeneous sample of employees recruited from two organizations. Recruitment of participants for Study 4 was challenging. Instead of determining the sample size based on a priori power analyses, we simply tried to recruit as many participants as we could. The hypotheses of Study 4a were as follows. Those with relatively high self-reported levels of the Dark Triad were expected to be perceived by their peers as (1) being on unfriendly terms with their coworkers, (2) less likely to engage in OCB, (3) more likely to engage in $\mathrm{CWB}$, and (4) more likely to engage in corruption. Furthermore, self-ratings were expected to be associated with peer ratings (5) on the HEXACO PI-R and (6) on a list of adjectives. Study $4 \mathrm{~b}$ hypothesized that the involved employees' self-ratings on the SD3-HU would be consistent with their supervisors' ratings of their (1) job performance and (2) workplace behavior.

\section{Study 4a. Associations between the Dark Traits and Peer Ratings in a Heterogeneous Sample}

\section{Method}

\section{Participants and Procedure}

A total of 69 full-time employees (20 men and 49 women) participated in the study. The mean age of the sample was 40.68 years $(S D=11.05)$. Of the 69 participants, 60 were 
employees and 9 were middle managers. Peer ratings were given by a total of 121 coworkers. Most participants were rated by two coworkers, except 16 participants, who were rated by only one coworker. As to the peer raters' formal relations to the respective targets, 96 peer raters were direct colleagues at the same level, 9 were supervisors, 8 were subordinates, 6 worked at a different unit of the same organization, and 2 did not respond. We did not exclude any participants from the analyses. All peer raters rated the general quality of their workplace relationships with the respective targets using a seven-point scale ranging from We are on extremely bad terms (1) to We are on extremely good terms (7). Most peer raters reported to have been on extremely friendly terms with the targets $(M=6.30$, $S D=1.10)$. Of the 121 peer raters, 31 had been coworkers with the respective targets for less than 1 year, 38 for 1 to 2 years, 14 for 3 to 4 years, 19 for 5 to 10 years, 18 for more than 10 years, and 1 peer rater did not respond.

The participants were recruited by snowball sampling conducted via social media and personal contacts. Those prospective participants who accepted the invitation were presented with an online form that contained the SD3$\mathrm{HU}$ and basic demographic questions. At the bottom of the form, the participants were asked to enter an ID code in a designated textbox and then to share the provided link to another form prepared for the peer raters with two coworkers of their own choice. Each responsive peer rater entered the ID code in a designated textbox at the top of the respective form, which enabled data alignment. The peer raters rated the targets on the following dimensions, respectively: the quality of the peer rater's workplace relationship with the target, the quality of the target's workplace relationships, organizational citizenship behaviors, counterproductive work behaviors, corruption intention, broad personality traits, cynicism, and other personal characteristics (assessed with a list of adjectives). Peer raters did not see the other rater's evaluation of the participant.

\section{Instruments}

Administered only to the participants (targets).

\section{Dark Triad}

The dark traits were measured with the SD3-HU developed in Study 1. The participants (targets) also provided basic demographic data.

Administered only to the raters (the raters rated the participants independently from each other).

\section{Negative Quality of Workplace Relationships}

The following seven items were designed by the authors to measure the peer raters' perceptions of the respective targets' workplace relationships with their coworkers: Our coworkers like my colleague (reverse-scored item); Our coworkers avoid my colleague; My colleague's behavior often gives rise to conflict in her/his team; My colleague's behavior often hinders her/his team's work; My colleague's behavior often impairs her/his team's performance; My colleague's behavior often gives rise to hostility in her/his team; My colleague's behavior often gives rise to work-related disagreement in her/his team. The peer raters rated each item on a seven-point scale ranging from Strongly disagree (1) to Strongly agree (7). An exploratory factor analysis with maximum likelihood estimation and promax rotation revealed that the seven items formed one factor. Accordingly, the sum of the item scores was used as a measure of the negative quality of the target's workplace relationships (Cronbach's $\alpha=.91)$.

\section{Organizational Citizenship Behaviors}

Organizational citizenship behaviors (OCBs) were assessed by a 14-item scale developed by Williams and Anderson (1991), which measures one's tendency to engage in two types of OCB with seven items each, including OCBs towards the organization as a whole (OCB-O; e.g., Conserves and protects organizational property) and $\mathrm{OCBs}$ towards individuals (OCB-I; e.g., Goes out of way to help new employees). The peer raters rated each item using a five-point scale ranging from Very much unlike my colleague (1) to Very much like my colleague (5). Both the OCB-I and OCB-O measures showed adequate internal consistency (Cronbach's $\alpha=.93$ and .80, respectively).

\section{Counterproductive Work Behaviors}

Counterproductive work behaviors were assessed with the Counterproductive Work Behavior Checklist also used in Study 3 (CWB-C; Spector et al., 2010). The peer raters rated each item using a five-point scale ranging from Very mисh unlike my colleague (1) to Very much like my colleague (5). The mean score of the 10 items was used as an overall measure of counterproductive work behaviors (Spector et al., 2010). The overall measure showed adequate internal consistency (Cronbach's $\alpha=.85$ ).

\section{Corruption Intention}

Corruption Intention was assessed with six hypothetical scenarios designed by the authors. Each scenario described a work-related situation involving corruption. The peer raters 
rated the extent to which they thought the respective targets would be willing to engage in the corrupt behavior described in each scenario, using a seven-point scale ranging from $M y$ colleague would definitely not be willing [to engage in the described behavior] (1) to My colleague would definitely be willing [to engage in the described behavior] (7). An example of the hypothetical scenarios is as follows. Imagine your colleague works for a company's procurement department. One potential supplier offers your colleague an expensive cell phone as a gift. Do you think your colleague would be willing to accept the gift? The mean score for the six items was used as a measure of perceived corruption intention. The six-item scale showed adequate internal consistency $(\alpha=.88)$

\section{Broad Personality Dimensions}

Six broad personality dimensions were assessed with the 60-item HEXACO-PI-R Observer Report Form (Lee \& Ashton, 2004). The peer raters rated the respective targets on each item a five-point scale ranging from Strongly disagree (1) to Strongly agree (5). The HEXACO-PI-R Observer Report Form measures the following personality dimensions: Honesty-Humility (e.g., He/she would never accept a bribe, even if it were very large; $\alpha=.81$ ), Emotionality (e.g., He/she worries about little things; $\alpha=.72$ ), Extraversion (e.g., He/she prefers jobs that involve active social interaction to those that involve working alone; $\alpha=.70$ ), Agreeableness (e.g., He/she is usually quite flexible in his/ her opinions when people disagree with him/her; $\alpha=.60$ ), Conscientiousness (e.g., He/she plans ahead and organizes things, to avoid scrambling at the last minute; $\alpha=.81$ ), Openness to experience (e.g., He/she would be quite bored by $a$ visit to an art gallery; $\alpha=.79$ ).

\section{Cynicism}

Cynicism was measured with one item (I consider the target a cynical person). The peer raters rated the respective targets on a five-point scale ranging from Strongly disagree (1) to Strongly agree (5).

\section{Personal Characteristics}

A list of 20 adjectives was designed by the authors to measure further personal characteristics. The peer raters rated the respective targets on each item using a seven-point scale ranging from Very much unlike my colleague (1) to Very much like my colleague (5). The list consisted of the following adjectives: aggressive, arrogant, attention-seeking, callous, cold, cruel, domineering, envious, evil, flattering, heartless, impetuous, malevolent, manipulative, overcompetitive, quick-tempered, reckless, self-important, selfish, vindictive. An exploratory factor analysis with maximum likelihood estimation and promax rotation revealed that 19 of the 20 adjectives formed three factors, which were labeled according to their contents as follows: emotional detachment (callous, malevolent, cruel, heartless, envious, evil, domineering, cold, overcompetitive; $\alpha=.94)$, social arrogance (self-important, arrogant, selfish, reckless, vindictive, manipulative; $\alpha=.91$ ), and impulsivity (impetuous, quick-tempered, attention-seeking; $\alpha=.81$ ). The adjective flattering did not load on any of the three factors.

\section{Results and Discussion}

Table 5 presents the associations of the three self-report trait measures of the SD3-HU and the respective peer ratings on each of the assessed dimensions.

The following results were obtained for the peer-rated workplace outcomes. Participants with higher levels of self-reported psychopathy were more likely to be perceived by their peers as being on bad terms with their coworkers and as prone to engage in counterproductive work behaviors. A marginally significant positive relationship was also observed between self-reported psychopathy and peer-rated corruption intention. Participants with higher levels of narcissism were perceived by their peers as less likely to engage in organizational citizenship behaviors while more likely to engage in counterproductive work behaviors and in corruption (the correlation obtained for this latter was only marginally significant). No significant association was found between self-reported Machiavellianism and any of the peer-rated workplace outcomes.

The major findings obtained for the peer-rated broad personality dimensions and specific personal characteristics were as follows. All three dark traits were negatively associated with peer-rated agreeableness. Participants reporting high levels of either dark trait were perceived by their peers as less agreeable and less cooperative. Both narcissism and psychopathy (but not Machiavellianism) were negatively associated with peer-rated honesty-humility. Highly narcissistic participants were perceived by their peers as highly extraverted. All three dark traits positively correlated with peer-rated cynicism. Participants high either on psychopathy or on narcissism were perceived as more emotionally detached, more socially arrogant, and more impulsive. By contrast, Machiavellianism was not associated with any of these personal characteristics.

The mentioned results are consistent with the related previous findings on the essential features of each dark trait: the aggressive, impulsive, self-centered and amoral behavior associated with subclinical psychopathy, and the egocentrism and defensive aggression characteristic to subclinical narcissism (Paulhus \& Williams, 2002; Jones \& Paulhus, 2014). It is not surprising that 
Table 5 Associations Between Dark Personality Traits and All Study Variables (S4a, S4b)

Study $4 \mathrm{a}(N=69)$ : The associations between dark personality traits and peer ratings

\begin{tabular}{llll}
\hline & Mach & Narc & Psych \\
\hline Negative Quality of Workplace Relationships & -.030 & .11 & $.21^{*}$ \\
OCB-O & -.07 & $-.24^{*}$ & -.12 \\
OCB-I & -.03 & -.09 & -.10 \\
CWB & .15 & $.24^{* *}$ & $.24^{* *}$ \\
Corrupt Intention & .12 & $.17^{\dagger}$ & $.17^{\dagger}$ \\
HH & -.13 & $-.22^{*}$ & $-.22^{*}$ \\
EM & -.15 & -.11 & $-.18^{*}$ \\
X & .06 & $.26^{* *}$ & .06 \\
C & .02 & -.07 & -.13 \\
O & -.06 & .12 & -.15 \\
A & $-.18^{*}$ & $-.26^{* *}$ & $-.32^{* *}$ \\
Cynicism & $.20^{*}$ & $.33^{* *}$ & $.28^{* *}$ \\
Emotional Detachment & .06 & $.16^{\dagger}$ & $.22^{*}$ \\
Social Arrogance & .05 & $.26^{* *}$ & $.18^{*}$ \\
Impulsivity & .03 & $.38^{* *}$ & $.34^{* *}$ \\
$\alpha$ & 0.80 & 0.73 & 0.77
\end{tabular}

Study $4 \mathrm{~b}(N=45)$ : The associations between dark personality traits and direct supervisor ratings

Overall level of work performance

Dependability

Professional Skills

Communicational Skills

Productivity

Preciseness

Initiative

Efficiency

Work-related judgment

Trustworthiness

Problem-solving ability

In general, the evaluated person knows what steps needs to be made in order to solve work issues

Helps co-workers with heavy workload

Goes the extra mile in his/her job

Impulsiveness

Likes to be in the center of attention

Generates conflicts in his/her work unit

Slow in his/her job

Prone to make mistakes

Decisiveness

\begin{tabular}{|c|c|c|}
\hline Mach & Narc & Psych \\
\hline-.16 & -.05 & $-.32 * *$ \\
\hline-.03 & -.14 & $-.37^{* *}$ \\
\hline-.04 & -.00 & $-.31^{* *}$ \\
\hline-.09 & -.09 & $-.35^{* *}$ \\
\hline-.03 & -.04 & $-.27^{\dagger}$ \\
\hline-.15 & -.20 & $-.39^{* *}$ \\
\hline .03 & $.30 * *$ & -.06 \\
\hline .15 & .04 & -.11 \\
\hline-.17 & -.15 & $-.34^{*}$ \\
\hline-.09 & -.02 & -.18 \\
\hline-.11 & -.10 & $-.31^{*}$ \\
\hline .04 & .02 & -.14 \\
\hline$-.27^{\dagger}$ & .10 & -.06 \\
\hline-.19 & -.07 & -.24 \\
\hline .20 & $.38 * *$ & $.48^{* * *}$ \\
\hline .19 & $.41^{* *}$ & $.28^{\dagger}$ \\
\hline .17 & $.29^{\dagger}$ & $.35^{*}$ \\
\hline-.02 & -.03 & .03 \\
\hline .09 & .12 & $.28^{\dagger}$ \\
\hline-.04 & .00 & -.22 \\
\hline 0.71 & 0.65 & 0.64 \\
\hline
\end{tabular}

Notes. Mach $=$ Machiavellianism, Narc $=$ Subclinical Narcissism, Psych $=$ Subclinical Psychopathy, OCB-O = Organizational Citizenship Behaviors Towards the Organization, OCB-I=Organizational Citizenship Behaviors Towards Individuals, EX=Extraversion, $\mathrm{EM}=$ Emotionality, $\mathrm{AG}=$ Agreeableness, $\mathrm{CO}=$ Conscientiousness, $\mathrm{OP}=$ Openness, $\mathrm{HH}=$ Honesty-Humility

$* p<.05, * * p<.01$
Machiavellianism was the least closely related to peer ratings. Highly Machiavellian individuals are well known to be manipulative strategists in their interpersonal dealings. They are often referred to as social chameleons who flexibly adapt their behavior to perceived environmental expectations in order to gain anticipated benefits (O'Boyle et al., 2012). For example, they are ready to display organizational citizenship behaviors when their own interest so requires (Szabó et al., 2018). Several recent studies have revealed the characteristics of high-Machs' behavioral adaptation to their supervisors' leadership style (e.g., Belschak et al., 2015), and the soft tactics they use to achieve their goals, which are also beneficial for their organization (Jonason et al., 2012). Bereczkei $(2015,2018)$ describes a repertoire of cognitive abilities which enable individuals high in Machiavellianism to flexible adapt to the social context. They can disguise or display their selfishness depending on the presence of others, they can effectively influence over other people even in the long run, and they can distinguish between strategic and non-strategic situations. This flexibility can manifest itself in very different behavioral strategies (e.g., the willingness to engage in OCB or the avoidance of CWB motivated by selfish and manipulative reasons).

\section{Study 4b. Associations between the Dark Traits and Peer Ratings in a Homogeneous Sample}

\section{Method}

\section{Participants and Procedure}

A total of 45 employees recruited from two organizations participated in the study. We did not exclude any participants from the analyses. The employees of both organizations participated in a validity study of an ability test and a Big-Fivebased test, as part of which they completed the SD3-HU, while peer ratings were collected from their supervisors. No demographic data were collected from the participants, since they were individually identified by name for data alignment purposes. The participants' names were removed from the obtained dataset after alignment. All participants gave informed consent to participation at each stage including the completion of the large test battery, the collection of supervisor ratings, and the completion of the SD3-HU, respectively.

Administered Only to the Participants (Targets) Dark Triad The dark traits were measured with the SD3-HU developed in Study 1. 
Administered Only to the Raters (the Direct Supervisors of the Participants)Supervisor Ratings The supervisors rated their employees on 20 items. Of these items, 11 concerned the targets' job performance, which assessed the following performance features and employee skills: general quality of performance, reliability of performance, expertise, communication skills, productivity, accuracy, initiative, efficiency, insight, fairness, problem solving skills. The supervisors rated each item using a five-point scale ranging from Poor (1) to Excellent (5). The remaining nine items assessed the targets' workplace behavior on the following dimensions: is generally aware how to work efficiently, helps colleagues with increased workload, contributes to productivity above expectations, is impulsive on the job, enjoys being in the center of her/his colleagues'/clients' attention, her/his behavior often gives rise to conflict in her/his team, is slow on the job, prone to mistakes, quick on decision making. The supervisors rated each item using a five-point scale ranging from Strongly disagree (1) to Strongly agree (5).

\section{Results}

Table 5 presents the correlations of the three DT measures with the respective supervisor ratings, along with the descriptive statistics and the Cronbach's $\alpha$ coefficients for the DT measures.

The data show that Machiavellianism had a marginally significant negative correlation with one item for organizational citizenship behaviors (Helps coworkers who have heavy workload), while none of the other peer-rated characteristics was related to self-reported Machiavellianism. Narcissism was positively associated with initiative, impulsivity, attention seeking, and conflict generation, while it did not show any significant negative associations. Among the three dark traits, the supervisor ratings were most closely related to psychopathy. Those employees with high self-reported psychopathy were perceived by their supervisors as relatively poor performers (eight of the 11 performance-related items were negatively associated with psychopathy). Their workplace behavior was also judged to be problematic, being associated with features such as impulsivity, attention seeking, conflict generation, and proneness to mistakes. These results are consistent with related previous findings pointing out that subclinical psychopathy is the most demanding trait in workplace contexts, while narcissism has several positive aspects (e.g., initiative) besides its dark side (e.g., conflict generation).

\section{General Discussion}

The present studies were aimed at the development of a reliable and valid Hungarian version of the SD3. The factor structure of the translated items and validity of the SD3-HU were tested on data collected from a total of seven independent samples. The obtained findings are generally consistent with those obtained with the original SD3 and its other adaptations, which suggests that the SD3-HU is a reliable and valid measure of the DT (Jones \& Paulhus, 2014; Persson et al., 2017; Zhang et al., 2020).

The results of Study 1 on the internal structure of the SD3-HU confirmed the expected bifactor structure including three specific dark factors with cross-loadings allowed and a general dark factor, although it did not in all respects meet the expectations. Specifically, some items showed lower (or zero) loadings on their respective specific factors compared to their loadings on the general factor, and the fit indices of the selected theoretical model fell somewhat short of the expectations, similarly to those obtained for other SD3 versions (e.g., Zhang et al., 2020). The internal consistency and intercorrelations of the dark trait measures are comparable to those of the original SD3 (Jones \& Paulhus, 2014).

The construct validity of the SD3-HU proved adequate. Each of the three dark trait measures showed the expected correlations with measures of broad personality dimensions, character strengths and sensation seeking. Specifically, all three dark traits showed significant negative correlations with honesty-humility and agreeableness, while narcissism was positively related to extraversion, and psychopathy was negatively related to conscientiousness. Emotionality was negatively associated both with narcissism and with psychopathy. The assessed character strengths were unrelated to Machiavellianism, while they were mostly negatively associated with psychopathy, and both positive and negative associations were found for narcissism, in line with the relevant literature. Sensation seeking was positively associated with all three dark traits.

The results on the concurrent validity of the SD3-HU were also consistent with the conceptualization of the DT. All three dark traits had positive correlations with selfreported CWB, while the related regression analysis revealed that subclinical psychopathy was the most important trait underlying such behaviors. The associations observed between the DT and work motivation revealed a complex picture. Machiavellianism and psychopathy showed similar but not identical patterns of work motives, both associated with the prominence of amotivation and extrinsic regulation as opposed to intrinsic motivation. Unlike psychopathy, Machiavellianism was also related to external social regulators, and not just to external material regulations. Narcissism was positively related to intrinsic motivation and identified regulation, while unrelated to amotivation. These results are consistent with previous findings on the positive associations of narcissism with achievement motivation and performance orientation (e.g., Andreassen et al., 2012; Gersenberg et al., 2014). 
An essential source of information on the validity of a self-report personality measure is the consistency between self-ratings and peer ratings. Study 4 involving both heterogeneous and homogeneous samples of employees provided such information on the SD3-HU. All three dark trait measures showed adequate self-peer convergent validity. Those with high self-reported subclinical psychopathy were more likely to be perceived by their peers as being on bad terms with their coworkers and prone to CWB and corruption. Compared to other participants, these individuals were judged to be less honest/humble, less emotional and less agreeable, while being cynical, emotionally detached, arrogant and impulsive. Their supervisors reported problems with both their job performance and workplace behavior. The observed individual differences in self-reported narcissism were likewise consistent with peer ratings. Highly narcissistic participants were perceived as less agreeable and more extraverted than others, and they were judged to be more prone to CWB and less willing to engage in OCB. Furthermore, these participants were reported to be impulsive, arrogant, attention-seeking, and prone to generate conflicts in their teams. Among the three dark traits, Machiavellianism was the least closely related to peer ratings, presumably due to highly Machiavellian individuals' mastery in manipulation and to their flexible adaptation to changing environmental expectations in the constant pursuit of selfinterest. The findings of Study $4 \mathrm{~b}$ deserve particular attention. In this study, the involved employees were individually evaluated by their supervisors in terms of job performance and workplace behavior, while they relinquished anonymity when providing self-report data on their dark traits. In this situation, the employees might understandably feel much at stake, even though special care was paid to the fully confidential treatment of each employee's and each supervisor's responses with the informed consent of all participants. Still, the obtained findings confirmed the expectations: subclinical psychopathy was associated with poor job performance and problematic work behaviors, narcissism was only associated with the latter, while Machiavellianism was unrelated to the supervisors' perceptions.

While the main aim of our studies was to adopt and validate the Hungarian version of the SD3, our findings also relate to important theoretical debates about the nature of dark triad personality traits. First, our findings show that subclinical narcissism is brighter than the other two DT traits in terms of character strengths, motivations, and positive workplace behaviors. For instance, recent studies showed that narcissism is associated with increased mental toughness, and this in turn, lead to positive outcomes (Papageorgiou et al., 2019). A study by Paunonen et al. (2006) found that the best rated leaders among military cadets were high in positive aspects of narcissism such as egotism and self-esteem. Our findings dovetail nicely with these studies.
Second, our findings contribute to the Machiavellianismpsychopathy redundancy debate. We found that Machiavellianism and psychopathy were very similar in terms of broad personality traits (low A, low $\mathrm{HH}$ ), but they differed from each other in terms of character strengths, motivations, and the perceptions of others. Compared to psychopathy, and also to narcissism, it is harder to describe what exactly constitutes Machiavellianism. In our studies, individuals high in Machiavellianism were characterized by low agreeableness, low honesty-humility (although not by peer raters), cynicism, and some negative character. It was also evident that they could be mainly motivated by extrinsic regulators (both material and social), and they may have motivational problems (higher levels of amotivation). It is astonishing that the self-rated Machiavellianism of participants almost had no relationship with other-rated behaviors and dispositions of the participants. Psychopathy, on the other hand, was strongly related to both self-rated negative behaviors and dispositions and other-rated negative behaviors and dispositions. Our findings suggest that the differences between Machiavellianism and psychopathy are not located in the broad personality trait level (see for example Muris et al., 2017; Vize et al., 2018a, 2018b), but in more specific behaviors, traits, motivations, and most importantly in the perceptions of others. Our results indirectly can be interpreted as evidence of the behavioral flexibility of Machiavellianism (see Bereczkei, 2015, 2018). According to Bereczkei (2018), Machiavellianism does not seem to be a fixed property of individuals but can primarily be shaped under the influence of environmental stimuli. In this sense, we can even question the adequacy of operationalizing Machiavellianism as a personality trait. It appears to be more of a philosophy of the individual to get ahead, manifesting itself in many different strategies, unlike psychopathy and narcissism which appears to be more trait-like. Morf and Rhodewalt (2001) presents a similar argument, arguing that individuals high in narcissism relatively lack in flexibility, and generally behave more trait-like. Third, our findings relate to an interesting area of research about Machiavellianism. Rauthmann and Kolar (2013) found that Machiavellians' interpersonal style is not agentic/dominant, contradicting the idea that they are strongly achievement and goal driven. Supporting this argument, our results show that Machiavellianism are mainly related to external regulators and amotivation.

Certain important limitations of our studies are worth noting. Most findings are based on self-report data, which might be heavily biased, given that dark personalities generally master impression management. No behavioral measures were administered to the participants (it was not a viable option), therefore the ecological validity of the SD3HU remains unclear. Most participants were highly educated white-collar workers actively using the social media, via which they were recruited. The employed snowball 
sampling method might result in adverse selection, that is, the invitation might primarily reach highly prosocial individuals responsive to cooperative effort rather than dark personalities highly motivated by self-interest. Some of the employed instruments showed inadequate reliability in terms of conventional standards. Study 4 was clearly underpowered because of the small sample sizes.

\section{Conclusion}

The most important conclusions of the present study are that (1) the SD3-HU is a reliable and valid measure of the dark traits in Hungarian workplace contexts (2) subclinical narcissism has more positive correlates than the other two dark triad personality traits (3) there are important differences between psychopathy and Machiavellianism in terms of character strengths, motivations, and workplace behaviors rated by informants and (4) Machiavellianism can be characterized by flexible behavior.

Data Availability Statement The datasets generated during and/or analyzed during the current study are available in the Open Science Framework repository, https://osf.io/8qsw3/?view_only=478a717ad2 $334 \mathrm{e} 6784172 \mathrm{e} 1 \mathrm{a} 8 \mathrm{cba} 634 \mathrm{c}$

Funding Information Open access funding provided by Budapest University of Technology and Economics. Project no. TKP2020-IKA-09 has been implemented with the support provided from the National Research, Development, and Innovation Fund of Hungary, financed under the 2020-4.1.1-TKP2020 funding scheme.

\section{Declaration}

Conflict of Interest The authors declare that there are no potential conflicts of interest with respect to the research, authorship, and/or publication of this article.

Compliance with Ethical Standards All procedures performed in studies involving human participants were in accordance with the ethical standards of the institutional research committee and with the 1964 Declaration of Helsinki and its later amendments or comparable ethical standards.

Open Access This article is licensed under a Creative Commons Attribution 4.0 International License, which permits use, sharing, adaptation, distribution and reproduction in any medium or format, as long as you give appropriate credit to the original author(s) and the source, provide a link to the Creative Commons licence, and indicate if changes were made. The images or other third party material in this article are included in the article's Creative Commons licence, unless indicated otherwise in a credit line to the material. If material is not included in the article's Creative Commons licence and your intended use is not permitted by statutory regulation or exceeds the permitted use, you will need to obtain permission directly from the copyright holder. To view a copy of this licence, visit http://creativecommons.org/licenses/by/4.0/.

\section{References}

Andó, B., Kökönyei, G., Paksi, B., Farkas, J., Rózsa, S., \& Demetrovics, Z. (2009). The 7-item brief sensation seeking scale (SSS7-HU). Journal of Mental Health and Psychosomatics, 10(2), 139-152. https://doi.org/10.1556/mental.10.2009.2.4

Andreassen, C. S., Ursin, H., Eriksen, H. R., \& Pallesen, S. (2012). The relationship of narcissism with workaholism, work engagement, and professional position. Social Behavior and Personality: An International Journal, 40(6), 881-890. https://doi.org/10.2224/ sbp.2012.40.6.881

Beauducel, A., \& Herzberg, P. Y. (2006). On the performance of maximum likelihood versus means and variance adjusted weighted least squares estimation in CFA. Structural Equation Modeling, 13(2), 186-203. https://doi.org/10.1207/s15328007sem1302_2

Beauducel, A., \& Wittmann, W. W. (2005). Simulation study on fit indexes in CFA based on data with slightly distorted simple structure. Structural Equation Modeling, 12(1), 41-75. https://doi.org/ 10.1207/s15328007sem1201_3

Belschak, F. D., Den Hartog, D. N., \& Kalshoven, K. (2015). Leading Machiavellians: How to translate Machiavellians' selfishness intro pro-organizational behavior. Journal of Management, 41(7), 1934-1956. https://doi.org/10.1177/0149206313484513

Bereczkei, T. (2015). The manipulative skill: Cognitive devices and their neural correlates underlying Machiavellian's decision making. Brain and Cognition, 99, 24-31. https://doi.org/10.1016/j. bandc.2015.06.007

Bereczkei, T. (2018). Machiavellian intelligence hypothesis revisited: What evolved cognitive and social skills may underlie human manipulation. Evolutionary Behavioral Sciences, 12, 32-51. https://doi.org/10.1037/ebs0000096

Dinić, B. M., \& Wertag, A. (2018). Effects of dark triad and HEXACO traits on reactive/proactive aggression: Exploring the gender differences. Personality and Individual Differences, 123, 44-49. https://doi.org/10.1016/j.paid.2017.11.003

Gagné, M., Forest, J., Vansteenkiste, M., Crevier-Braud, L., Van den Broeck, A., Aspeli, A. K., Bellerose, J., Benabou, C., Chemolli, E., Güntert, S. T., Halvari, H., Indiyastuti, D. L., Johnson, P. A., Molstad, M. H., Naudin, M., Ndao, A., Olafsen, A. H., Roussel, P., Whang, Z., \& Westbye, C. (2015). The multidimensional work motivation scale: Validation evidence in seven languages and nine countries. European Journal of Work and Organizational Psychology, 24(2), 178-196. https://doi.org/10.1080/1359432X. 2013.877892

Gersenberg, F. X. R., Imhoff, R., Banse, R., \& Schmitt, M. (2014). Discrepancies between implicit and explicit self-concepts of intelligence: Relations to modesty, narcissism, and achievement orientation. Frontiers in psychology, 5, article 85. https://doi.org/ 10.3389/fpsyg.2014.00085.

Goldberg, L. R., Johnson, J. A., Eber, H. W., Hogan, R., Ashton, M. C., Cloninger, C. R., \& Gough, H. C. (2006). The international personality item Pool and the future of public-domain personality measures. Journal of Research in Personality, 40(1), 84-96. https://doi.org/10.1016/j.jrp.2005.08.007

Górnik-Durose, M. E., \& Pilch, I. (2016). The dual nature of materialism How personality shapes materialistic value orientation. Journal of Economic Psychology, 57, 102-116. https://doi.org/ 10.1016/j.joep.2016.09.008

Hambleton, R. K. (2001). The next generation of the ITC test translation and adaptation guidelines. European Journal of Psychological Assessment, 17(3), 164-172. https://doi.org/10.1027//10155759.17.3.164 
Heene, M., Hilbert, S., Draxler, C., Ziegler, M., \& Bühner, M. (2011). Making misfit in confirmatory factor analysis by increasing unique variances: A cautionary note on the usefulness of cutoff values of fit indices. Psychological Methods, 16(3), 319-336. https://doi. org/10.1037/a0024917

Jonason, P. K., Slomski, S., \& Partyka, J. (2012). The dark triad at work: How toxic employees get their way. Personality and Individual Differences, 52(3), 449-453. https://doi.org/10.1016/j.paid. 2011.11.008

Jonason, P. K., \& Webster, G. D. (2010). The dirty dozen: A concise measure of the dark triad. Psychological Assessment, 22(2), 420-432. https://doi.org/10.1037/a0019265

Jones, D. N., \& Paulhus, D. L. (2010). Different provocations trigger aggression in narcissists and psychopaths. Social Psychological and Personality Science, 1(1), 12-18. https://doi.org/10.1177/ 1948550609347591

Jones, D. N., \& Paulhus, D. L. (2014). Introducing the short dark triad (SD3) a brief measure of dark personality traits. Assessment, 21(1), 28-41. https://doi.org/10.1177/1073191113514105

Kaufman, S. B., Yaden, D. B., Hyde, E., \& Tsukayama, E. (2019). The light vs. dark triad of personality: Contrasting two very different profiles of human nature. Frontiers in Psychology, 10, 467. https:// doi.org/10.3389/fpsyg.2019.00467

Kessler, S. R., Bandelli, A. C., Spector, P. E., Borman, W. C., Nelson, C. E., \& Penney, L. M. (2010). Re-examining Machiavelli: A three-dimensional model of Machiavellianism in the workplace. Journal of Applied Social Psychology, 40(8), 1868-1896. https:// doi.org/10.1111/j.1559-1816.2010.00643.x

Lee, K., \& Ashton, M. C. (2004). Psychometric properties of the HEXACO personality inventory. Multivariate Behavioral Research, 39(2), 329-358. https://doi.org/10.1207/s15327906mbr3902_8

Lee, K., \& Ashton, M. C. (2005). Psychopathy, Machiavellianism, and narcissism in the five-factor model and the HEXACO model of personality structure. Personality and Individual Differences, 38(7), 1571-1582. https://doi.org/10.1016/j.paid.2004.09.016

Lee, K., \& Ashton, M. C. (2014). The dark triad, the big five, and the HEXACO model. Personality and Individual Differences, 67, 2-5. https://doi.org/10.1016/j.paid.2014.01.048

Lee, K., Ashton, M. C., Wiltshire, J., Bourdage, J. S., Visser, B. A., \& Gallucci, A. (2013). Sex, power, and money: Prediction from the dark triad and honesty-humility. European Journal of Personality, 27(2), 169-184. https://doi.org/10.1002/per.1860

Marsh, H. W., Morin, A. J. S., Parker, P. D., \& Kaur, G. (2014). Exploratory structural equation modeling: An integration of the best features of exploratory and confirmatory factor analysis. Annual Review of Clinical Psychology, 10, 85-110. https://doi.org/10. 1146/annurev-clinpsy-032813-153700

Martinsen, Ø. L., Arnulf, J. K., Furnham, A., \& Lang-Ree, O. C. (2019). Narcissism and creativity. Personality and Individual Differences, 142, 166-171. https://doi.org/10.1016/j.paid.2018. 09.032

Morf, C. C., \& Rhodewalt, F. (2001). Unraveling the paradoxes of narcissism: A dynamic self-regulatory processing model. Psychological Inquiry, 12, 177-196. https://doi.org/10.1207/S1532 7965PLI1204_1

Mundfom, D. J., Shaw, D. G., \& Lu Ke, T. (2009). Minimum sample size recommendations for conducting factor analyses. International Journal of Testing, 5, 159-168. https://doi.org/10.1207/ s15327574ijt0502_4

Muris, P., Merckelbach, H., Otgaar, H., \& Meijer, E. (2017). The malevolent side of human nature: A meta-analysis and critical review of the literature on the dark triad (narcissism, Machiavellianism, and psychopathy). Perspectives on Psychological Science, 12, 183-204. https://doi.org/10.1177/1745691616666070

Muthén, L. K., \& Muthén, B. (1998-2017). Mplus user's guide. Muthén \& Muthén.

O’Boyle, E. H., Forsyth, D. R., Banks, G. C., \& McDaniels, M. A. (2012). A meta-analysis of the dark triad and work behavior: A social exchange perspective. Journal of Applied Psychology, 97(3), 557-579. https://doi.org/10.1037/a0025679

Papageorgiou, K. A., Gianniou, F.-M., Wilson, P., Moneta, G. B., Bilello, D., \& Clough, P. J. (2019). The bright side of dark: Exploring the positive effect of narcissism on perceived stress through mental toughness. Personality and Individual Differences, 139(1), 116-124. https://doi.org/10.1016/j.paid.2018.11.004

Patton, C. L., Smith, S. F., \& Lilienfeld, S. O. (2018). Psychopathy and heroism in first responders: Traits cut from the same cloth? Personality Disorders: Theory, Research, and Treatment, 9(4), 354-368. https://doi.org/10.1037/per0000261

Paulhus, D. L., \& Williams, K. M. (2002). The dark triad of personality: Narcissism, Machiavellianism, and psychopathy. Journal of Research in Personality, 36(6), 556-563. https://doi.org/10.1016/ S0092-6566(02)00505-6

Paunonen, S. V., Lönnqvist, J.-E., Verkasalo, M., Leikas, S., \& Nissinen, V. (2006). Narcissism and emergent leadership in military cadets. The Leadership Quarterly, 17(5), 475-486. https:// doi.org/10.1016/j.leaqua.2006.06.003

Persson, B. N., Kajonius, P. J., \& Garcia, D. (2017). Revisiting the structure of the short dark triad. Assessment, 26(1), 3-16. https:// doi.org/10.1177/1073191117701192

Peterson, C., \& Seligman, M. E. P. (2004). Character strengths and virtues: A handbook and classification. Oxford University Press.

Prusik, M., \& Szulawski, M. (2019). The relationship between the dark triad personality traits, motivation at work, and burnout among HR recruitment workers. Frontiers in Psychology. https://doi.org/ 10.3389/fpsyg.2019.01290

Rauthmann, J. F., \& Kolar, G. P. (2013). Positioning the dark triad in the interpersonal circumplex: The friendly-dominant narcissist, hostile-submissive Machiavellian, and hostile-dominant psychopath? Personality and Individual Difference, 54, 622-627. https:// doi.org/10.1016/j.paid.2012.11.021

Rosenthal, S. A., \& Pittinsky, T. L. (2006). Narcissistic leadership. The Leadership Quarterly, 17(6), 617-633. https://doi.org/10.1016/j. leaqua.2006.10.005

Rosseel, Y. (2012): Lavaan: An R package for structural equation modeling. Journal of statistical software, 48(2). https://doi.org/ 10.18637/jss.v048.i02.

Schönbrodt, F., \& Perugini, M. (2013). At what sample size do correlations stabilize? Journal of Research in Personality, 47, 609-612. https://doi.org/10.1016/j.jrp.2013.05.009

Spector, P. E., Bauer, J. A., \& Fox, S. (2010). Measurement artifacts in the assessment of counterproductive work behavior and organizational citizenship behavior: Do we know what we think we know? Journal of Applied Psychology, 95(4), 781-790. https://doi.org/ 10.1037/a0019477

Szabó, Z. P., Czibor, A., Restás, P., \& Bereczkei, T. (2018). “The darkest of all": The relationship between the dark triad traits and organizational citizenship behavior. Personality and Individual Differences, 134(1), 352-356. https://doi.org/10.1016/j.paid.2018. 04.026

Szabó, Z. P., Simon, E., Czibor, A., Restás, P., \& Bereczkei, T. (2021). The importance of dark personality traits in predicting workplace outcomes. Personality and Individual Differences, 183, 111112. https://doi.org/10.1016/j.paid.2021.111112 
Vize, C. E., Collison, K. L., Miller, J. D., Lynam, D. R., \& Back, M. (2018a). Examining the effects of controlling for shared variance among the dark triad using meta-analytic structural equation modelling. European Journal of Personality, 32, 46-61. https://doi. org/10.1002/per.2137

Vize, C. E., Lynam, D. R., Collison, K. L., \& Miller, J. D. (2018b). Differences among dark triad components: A meta-analytic investigation. Personality Disorders: Theory, Research, and Treatment, 9(2), 101-111. https://doi.org/10.1037/per0000222
Zhang, J., Ziegler, M., \& Paulhus, D. L. (2020). Development and evaluation of the short dark triad - Chinese version (SD3-C). Current Psychology: A Journal for Diverse Perspectives on Diverse Psychological Issues, 39(4), 1161-1171. https://doi.org/10.1007/ s12144-019-00272-3

Publisher's Note Springer Nature remains neutral with regard to jurisdictional claims in published maps and institutional affiliations. 